\title{
THE MIXED-PHASE ARCTIC CLOUD EXPERIMENT
}

by J. Verlinde, J. Y. Harrington, G. M. McFarquhar, V. T. Yannuzzi, A. Avramov, S. Greenberg, N. Johnson, G. Zhang, M. R. Poellot, J. H. Mather, D. D. Turner, E. W. Eloranta, B. D. Zak, A. J. Prenni, J. S. Daniel, G. L. Kok, D. C. Tobin, R. Holz, K. Sassen, D. Spangenberg, P. Minnis, T. P. Tooman, M. D. Ivey, S. J. Richardson, C. P. Bahrmann, M. Shupe, P. J. DeMott, A. J. Heymsfield, and R. Schofield

\author{
Liquid layers were observed in the Mixed-Phase Arctic Cloud Experiment (M-PACE) \\ at temperatures down to $-30^{\circ} \mathrm{C}$.
}

$\int$ ignificant and interrelated atmospheric, oceanic, and terrestrial changes have been occurring in the Arctic in recent decades (SEARCH SSC 2001; ACIA 2005). These changes are broad ranging, impacting every part of the Arctic environment. The Arctic is observed to be warming at a rate approximately twice that of the global average (ACIA 2005). Indeed, Overpeck et al. (2005) conclude, based on observations and model simulations, that the Arctic is heading toward a new climate state characterized by substantially less permanent ice. The uncertainty in the model projections, however, is larger in the Arctic than over the rest of the globe (Holland and Bitz 2003; Kattsov and Källén 2004). The underlying causes of this enhanced warming and scatter among models in the Arctic are not well understood, but are thought to be related to complex feedback processes unique to the Arctic. Arctic clouds have been identified as
AfFiliations: Verlinde, Harrington, Yannuzzi, Avramov, Greenberg, Richardson, and Bahrmann-The Pennsylvania State University, University Park, Pennsylvania; McFarQUHAR AND ZHANG—University of Illinois at Urbana-Champaign, Urbana, Illinois; Poellot-University of North Dakota, Grand Forks, North Dakota; MATHER-Pacific Northwest National Laboratory, Richland, Washington; TURNER, ELORANTA, TOBIN, AND HOLZ-University of Wisconsin-Madison, Madison, Wisconsin; ZAK AND IVEY-Sandia National Laboratories, New Mexico, Albuquerque, New Mexico; Prenni And DeMotT-Colorado State University, Fort Collins, Colorado; DANIEL-NOAA Earth System Research Laboratory, Boulder, Colorado; КоK-Droplet Measurement Technologies, Inc., Boulder, Colorado; SASSEN-University of Alaska, Fairbanks, Fairbanks, Alaska; SPANGENBERG-Analytical Services \& Materials, Inc., Hampton, Virginia; MINNIs—NASA Langley Research Center, Hampton, Virginia; ToomAN-Sandia National Laboratories, California, Livermore, California; HeYMSFIELD—National Center for
Atmospheric Research, Boulder, Colorado; SHUPE-The Cooperative Institute of Research in Environmental Sciences, University of Colorado, Boulder, Colorado; SCHOFIELD—NOAA Earth System Research Laboratory, Boulder, and The Cooperative Institute of Research in Environmental Sciences, University of Colorado, Boulder, Colorado CORRESPONDING AUTHOR: Hans Verlinde, 503 Walker Building, Department of Meteorology, The Pennsylvania State University, University Park, PA 16803

E-mail: verlinde@meteo.psu.edu

The abstract for this article can be found in this issue, following the table of contents.

DOI:10.1175/BAMS-88-2-205

In final form 13 July 2006

○2007 American Meteorological Society 
playing a central role in several hypothesized feedback processes (Curry et al. 1996; Vavrus 2004). The interactions among clouds, the over- and underlying atmosphere, and the ocean/sea ice surface are highly complex, arguably the most complex in the Northern Hemisphere. At the same time, these processes and their interactions are less well understood than lowerlatitude phenomena (Randall et al. 1998; Curry et al. 2000), the result of which is uncertainties in the feedback pathway. Francis et al. (2005) established a plausible link between cloud cover decreases in winter and increases in other seasons (Wang and Key 2003, 2005a,b), and decreases in the areal extent of sea ice in recent decades (Stroeve et al. 2005).

It is well known that Arctic low-level clouds are distinct from their lower-latitude counterparts. Weak solar heating, coupled with strong inversions and a combination of sea ice and ocean for a lower boundary produce clouds with multiple layers and stable temperature profiles (Curry 1986; Curry et al. 1990, 1996; Randall et al. 1998). Moreover, the recent Surface Heat and Energy Budget of the Arctic (SHEBA)/First International Satellite Cloud Climatology Project (ISCCP) Regional Experiment (FIRE)-Arctic Cloud Experiment (ACE) (Uttal et al. 2002; Curry et al. 2000) revealed that mixed-phase clouds appear to dominate the low-cloud fraction within the Arctic during the colder three-quarters of the year (Intrieri et al. 2002a; Wang et al. 2005). Arctic low-level mixed-phase clouds tend to be long lived, with liquid tops that continually precipitate ice (Pinto 1998; Hobbs and Rangno 1998; Curry et al. 2000). This longevity is somewhat perplexing given that the Bergeron process should cause rapid glaciation of these clouds (Harrington et al. 1999). Although SHEBA/FIRE-ACE enhanced our knowledge of Arctic clouds in general, and of mixedphase clouds in particular, much remains to be learned. Numerical modeling suggests that the ice phase heavily influences cloud evolution (Pinto and Curry 1995) and that heterogeneous ice nucleation controls mixed-phase longevity (Harrington et al. 1999; Jiang et al. 2000; Morrison et al. 2005). Our poor understanding of the nucleation mechanisms that control ice amounts in Arctic clouds has led to parameterizations that are based more on physical speculation than on observations (Harrington and Olsson 2001). Nevertheless, such parameterizations are important because cloud microphysics is intimately tied to cloud-scale dynamics (Harrington et al. 1999) and the underlying surface energy budget (Curry et al. 1997; Walsh and Chapman 1998; Intrieri et al. 2002b). Moreover, the radiative characteristic of these clouds are not fully understood (Pinto et al. 1999).

In order to help bridge the gaps in our understanding of mixed-phase Arctic clouds, the Department of Energy (DOE) Atmospheric Radiation Measurement (ARM) program (Stokes and Schwartz 1994; Ackerman and Stokes 2003) funded an integrated, systematic observational study. The major objective of the Mixed-Phase Arctic Cloud Experiment (M-PACE), conducted 27 September-22 October 2004 during the autumnal transition season, was to collect a focused set of observations needed to advance our understanding of the cloud microphysics, cloud dynamics, thermodynamics, radiative properties, and evolution of Arctic mixed-phase clouds. These data would complement the FIRE-ACE data collected during the spring transition season, expanding the set that can be used to improve both detailed models of Arctic clouds and large-scale climate models. The DOE ARM Climate Research Facility on the North Slope of Alaska (NSA) was chosen as the preferred location for this experiment. Long-term cloud and radiation climate measurements are being taken there, and properties of the oft-occurring mixedphase clouds retrieved from the surface-based remote sensing instruments must be evaluated and compared to results of the SHEBA/FIRE-ACE studies (Zuidema et al. 2005; Shupe et al. 2006). By virtue of its high latitude, Barrow experiences many close zenith overpasses by the National Aeronautics and Space Administration (NASA) Earth Observing System satellites, making it a good location to collect data to evaluate satellite retrieval products from the Arctic. Finally, M-PACE also sought to take advantage of recent advances in measurement technology and lessons learned from FIRE-ACE and other experiments by deploying a suite of remote sensing and in situ instruments that is capable of characterizing fully the properties of mixed-phase clouds.

The M-PACE experimental domain (Fig. 1) approximated a single-column-modeling (SCM) grid box to facilitate testing of climate model parameterizations in SCMs. The DOE ARM NSA site at Barrow (information available online at www.arm. gov/sites/nsa.stm) was supplemented with the High Spectral Resolution Lidar (HSRL; Eloranta 2005) from the University of Wisconsin-Madison and the University of Alaska Fairbanks depolarization lidar (Sassen 1994). The Pacific Northwest National Laboratory (PNNL) Atmospheric Remote Sensing Laboratory (PARSL; see information online at www. pnnl.gov/parsl) was deployed at Oliktok Point and was supplemented with a rapid-scan Atmospheric 
Emitted Radiance Interferometer (AERI) from the University of Wisconsin (Knuteson et al. 2004). Radiosonde launches were conducted from the four surface sites (Barrow, Atqasuk, Oliktok Point, and Toolik Lake) with a maximum of four sondes per day. Two instrumented aircraft participated in the experiment-the University of North Dakota (UND) Citation served as an in situ platform, whereas the Piloted Scaled Composites Proteus, sponsored by the DOE ARM Unmanned Aerospace Vehicle Program, served as a remote sensing aircraft flying above the cloud decks. In addition to the regular complement of cloud physics probes, the Citation flew a High Volume Precipitation Sampler (HVPS), the counterflow virtual impactor (CVI) from Droplet Measurement Technologies Cloud Spectrometer and Impactor for total water content, and the Colorado State University continuous-flow ice thermal diffusion chamber (CFDC). Together, these measurement systems documented the cloud properties while at the same time providing constraints for radiative transfer calculations above and below the cloud layers. A full set of the science questions and objective are presented in Table 1.

\section{OVERVIEW OF WEATHER AND MISSIONS.}

The synoptic-scale flow during M-PACE generally controlled the types, extent, and duration of the observed cloud cover. The North Slope of Alaska was under three different synoptic regimes with two transition periods during M-PACE. The first regime (regime I), between 24 September and 1 October, was unsettled. A pronounced trough aloft funneled several shortwave systems into the NSA. During this period the surface was dominated by three small, weak low pressure systems passing through the area with a large high pressure system northwest of the Alaskan coast over the Arctic Ocean. The first two case days, 29 and 30 September, occurred in the heart of this weather regime (Fig. 2a). Climatologically,

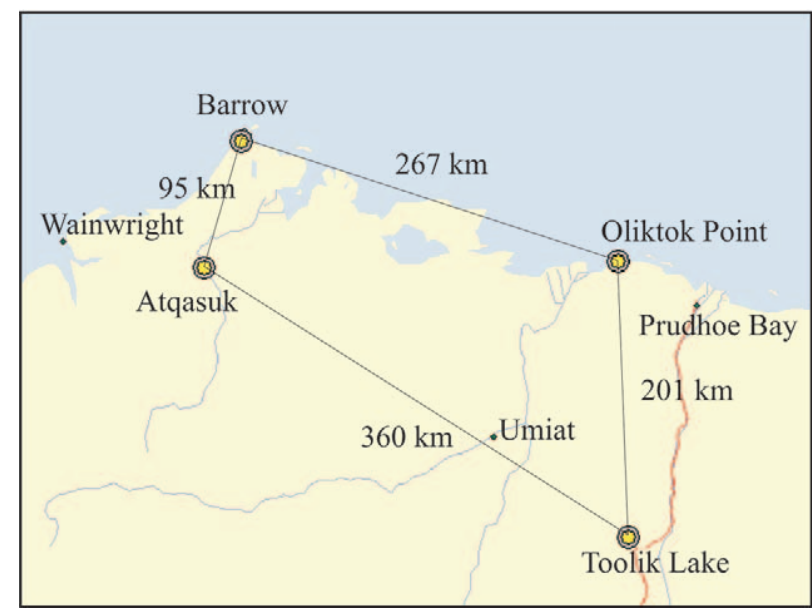

FIG. I. M-PACE experimental domain on the North Slope of Alaska. The operation center was located in Prudhoe Bay, southeast of Oliktok Point.

\section{TABLE I. M-PACE science questions and objectives.}

\section{M-PACE science questions}

I) How are mixed-phase cloud microphysics, radiation, and cloud dynamics linked?

2) How well are existing surface-based remote sensing instruments characterizing the macro- and microscopic characteristics of mixed-phase clouds?

3) What are the characteristics of Arctic midlevel clouds?

\section{M-PACE objectives}

I) Document horizontal structure and variability of the cloud microphysics and dynamics.

2) Document profiles of microphysics, particularly over the ground-based remote sensing sites and during satellite overpasses.

3) Obtain coincident radiance/irradiance data above/below cloud layers with in situ microphysical data.

4) Document impacts of multiple cloud layers on cloud characteristics and measurements.

5) Document the airmass ice freezing nuclei population characteristics.

6) Document impacts of variable surface characteristics on cloud properties.

7) Obtain measurements of scattering-phase function of different types of clouds.

8) Obtain measurements of water vapor profiles in cloudy and clear condition.

9) Obtain measurements of clear-sky emissivity.

10) Document the atmospheric structure at corners of grid box during cloudy events. 
a)

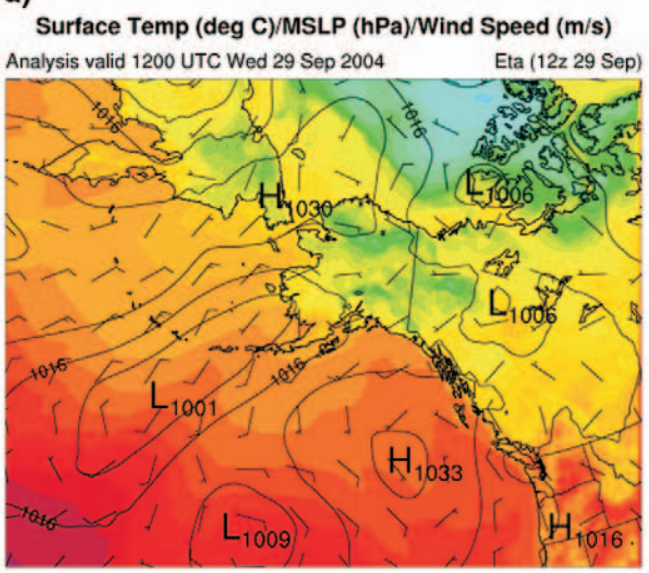

c)

\section{Surface Temp (deg C)/MSLP (hPa)/Wind Speed $(\mathrm{m} / \mathrm{s})$}

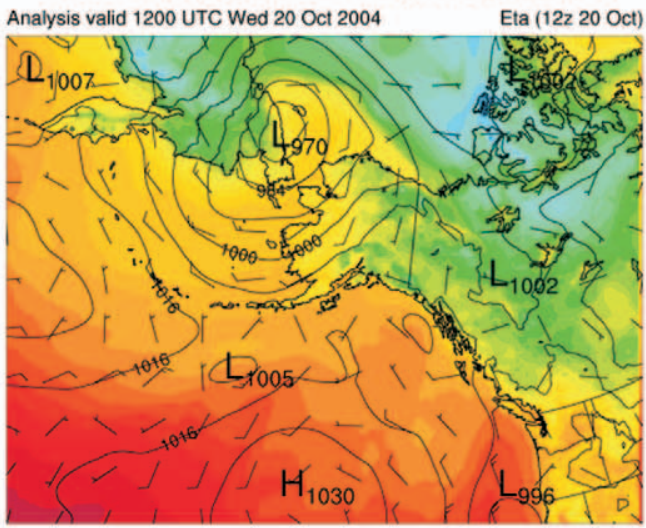

this regime was characterized by seasonal to slightly above average temperatures.

The transition period between regimes I and II was marked on 2-3 October. By 4 October, synoptic regime II was firmly in place with high pressure building over the pack ice to the northeast of the Alaska coast. This strong high dominated the NSA until 15 October. For the majority of the period, flow associated with the high pressure system originated out of either the east or east-northeast with considerable fetch over the Arctic Ocean before impinging on the Alaska coast (Fig. 2b). As the high pressure built over the pack ice, a small midlevel low pressure system drifted along the northern Alaska coast from 5 to 7 October, and dissipated between Deadhorse and Barrow on 7 October. This midlevel low brought a considerable amount of mid- and upper-level moisture to the NSA and was the source of the cloudiness experienced during the flight operation days of 5 and 6 October. By 8 October, temperatures over the pack ice had dropped considerably, reaching $\sim-20^{\circ} \mathrm{C}$ (Fig. 2), with a strengthening of the high. The sea ice line gradually advanced southward, allowing the b)

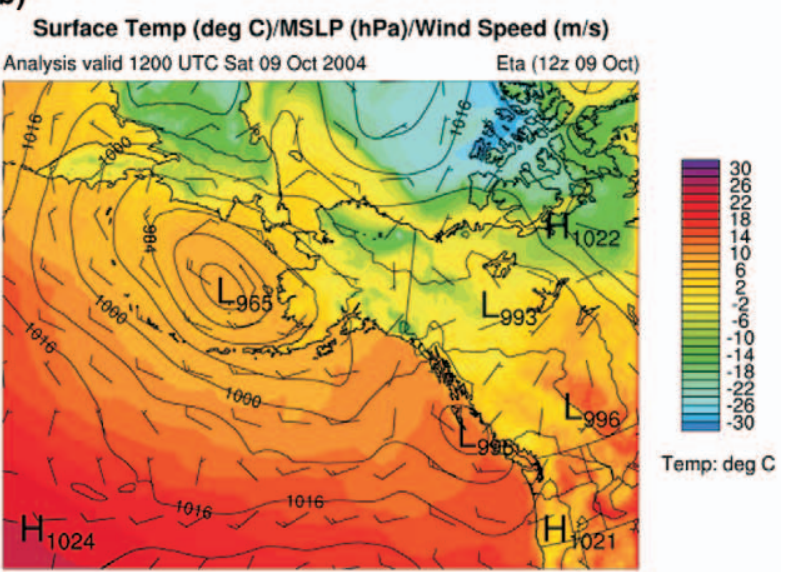

FIG. 2. Eta Model surface analyses from the three M-PACE synoptic regimes: (a) I200 UTC Wednesday 29 Sep 2004, (b) 1200 UTC Saturday 9 Oct 2004, and (c) 1200 UTC Wednesday 20 Oct 2004. Shown are temperatures (shaded), mean sea level pressure (contoured), and wind (barbs).

air cooled by the pack ice to reach the Alaskan coast along with boundary layer roll clouds (Fig. 3). This regime was the main driver of cloudiness during the 8-10 and 12 October case days. Climatologically, regime II brought above-average temperatures for the first half of the period (4-9 October) and more seasonal temperatures during the second half (10-13 October), associated with the weak trough. Exceptionally low diurnal temperature ranges were present for the entire period, with 9 of 11 days having diurnal ranges of $2^{\circ} \mathrm{C}$ or less.

The transition to regime III was marked on 1517 October. The surface high over the pack ice slowly

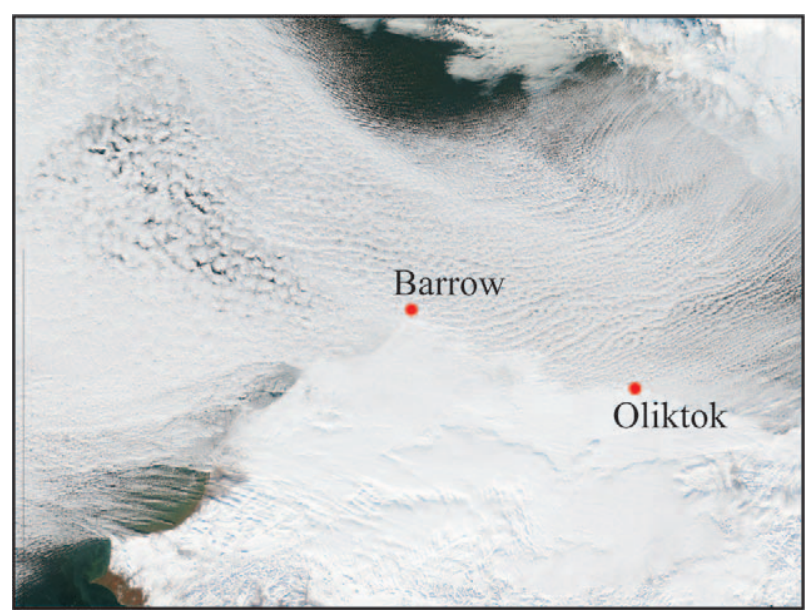

FIG. 3. MODIS visible image of the Arctic Ocean and northern Alaska 9 Oct 2004. 
drifted southeastward and was gone by 18 October, ushering in regime III. This period was marked by the influence of a strong and fast-developing low pressure center (940-hPa peak strength with a 42-hPa drop analyzed over $24 \mathrm{~h}$ ) that formed near Kamchatka and propagated north through the Bering Strait and eventually into the northwestern portion of the Chukchi Sea. The resulting synoptic regime produced southeasterly flow for much of the NSA (Fig. 2c). This flow pattern spawned periods where the NSA was under partially cloudy, or even clear, skies. Frontal systems spawned by the low strongly affected the NSA west of a line between Barrow and Oliktok Point, and deep clouds frequently occurred in the presence of these systems. Overall, the mean temperature was $\sim 5.5^{\circ} \mathrm{C}$ above average under regime III-the warmest of the three periods. For more detailed information concerning weather conditions, cloud data, and forecasts see http://nsa.met.psu.edu.

To provide a more objective classification of weather type during M-PACE, an automated classification procedure, consisting of principal component analysis (PCA) and a two-stage clustering routine, was used (Avramov 2005). The analysis is applied in two ways: the first categorizes the circulation patterns over Alaska (circulation approach), whereas the second categorizes the atmospheric thermodynamic profiles over Barrow (airmass approach). The circulation approach is most useful when the evaluation requires details pertaining to atmospheric transport mechanisms, while the airmass approach is preferred when the categories should be thermodynamically homogeneous (Kalkstein et al. 1996).

When applied to October months for the period from 1981 to 2003, the PCA/ clustering procedure identified 11 airmass clusters over Barrow and 11 circulation clusters over Alaska. These clusters or types were then used to categorize the synoptic conditions that took place during M-PACE, the results of which are displayed in Fig. 4. Here colors represent different cluster classifications, but otherwise have no significance. This analysis reveals that the M-PACE sampled only a small subset of possible
October circulation patterns; two patterns dominated, although four patterns were diagnosed on at least 3 days. In contrast, seven classifications of thermodynamic profiles were diagnosed on at least 3 days. Stable regimes may be identified when both the profiles and circulation classification remain unchanged for a period of days. The value of this analysis is that it allows the M-PACE findings to extend to, and to benefit from, a much longer time period of the ARM NSA data stream.

The Citation and the Proteus flew 13 and 5 missions, respectively, in support of M-PACE (flights days indicated with white Xs in Fig. 4). Summaries of the conditions for all flights are provided in Table 2. In total, 11 missions were dedicated to characterizing mixed-phase cloud microphysics and 2 flights to cirrus. Each aircraft diverted from its primary mis-

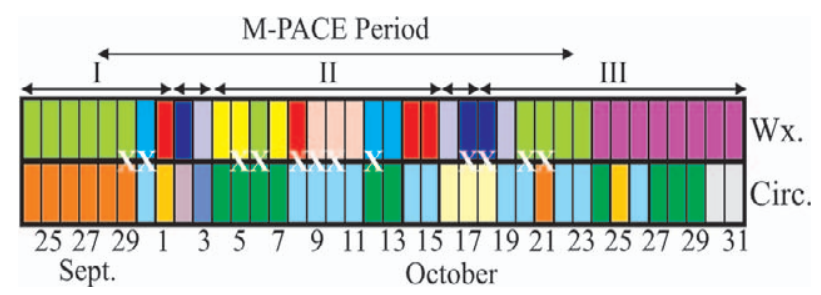

FIG. 4. Objective weather-type classification for each day of the September-October M-PACE period. Each color represents a different cluster. The upper bar shows thermodynamic profile classification (Wx) over Barrow, while the lower bar shows synoptic circulation clusters (CIRC). Aircraft mission days are indicated by white $X$ markers.

\begin{tabular}{|c|c|c|c|}
\hline Date & Category & $T_{\min }\left({ }^{\circ} \mathrm{C}\right)$ & FSSP $\left(\mathrm{cm}^{-3}\right)$ \\
\hline $29 \mathrm{Sep}$ & $B L S t$ & -15 & $70-90$ \\
\hline $30 \mathrm{Sep}$ & Multilayer St & -15.5 & $20-70$ \\
\hline $5 \mathrm{Oct}$ & Multilayer St & -6 & $100-400$ \\
\hline $6 \mathrm{Oct}$ & Multilayer St & -17 & $25-50$ \\
\hline $8 \mathrm{Oct}^{*}, * *$ & Multilayer St & -11 & $20-30$ \\
\hline 9 Oct $(a)^{*}$ & $\mathrm{BLSt}$ & -16 & $50-100$ \\
\hline 9 Oct (b) & $\mathrm{BLSt}$ & -15 & $60-150$ \\
\hline $100 \mathrm{ct}^{* * * *}$ & $\mathrm{BLSt}$ & -17 & $20-40$ \\
\hline $12 \mathrm{Oct}^{*}, * *$ & $\mathrm{BL} \mathrm{St}$ & -15 & $40-60$ \\
\hline 17 Oct**** & $\mathrm{Ci}$ & -57 & $50 \mathrm{~L}^{-1} 2 \mathrm{DC}$ \\
\hline $18 \mathrm{Oct}$ & $\mathrm{Ci}$ & -55 & $20 \mathrm{~L}^{-1} 2 \mathrm{DC}$ \\
\hline $20 \mathrm{Oct}$ & Aerosol/Sc & -13.5 & $10-30$ \\
\hline $21 \mathrm{Oct}$ & Aerosol/As & $-23 /-30$ & 15 \\
\hline
\end{tabular}




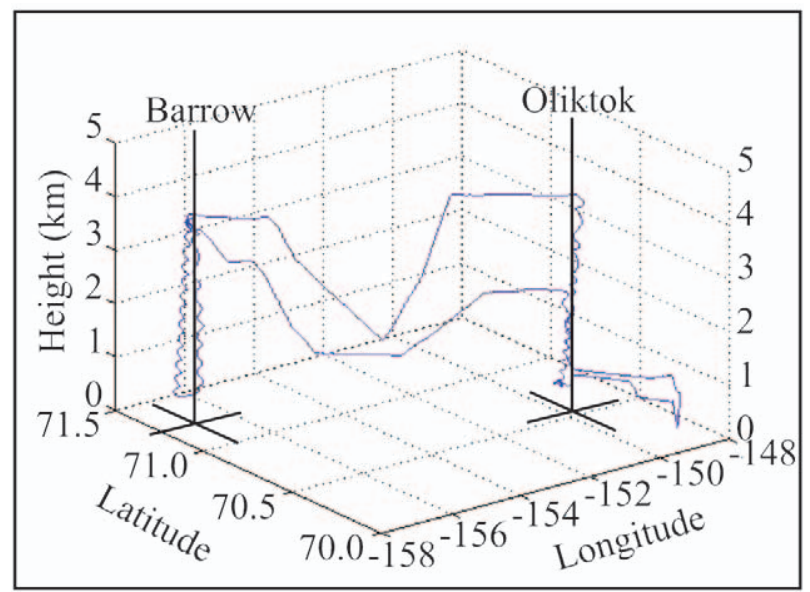

FIG. 5. Flight pattern of the UND Citation for the 6 October flight. The locations of the two primary ground-based remote sensing sites (Barrow and Atqasuk) are indicated.

sion on four occasions, three of which were coordinated to conduct measurements along the trajectory of overpassing satellites for the purpose of providing in situ and high-resolution remote sensing measurements for satellite retrieval evaluations. Ice-freezing nuclei (IN) concentrations were measured on all October flights but one. Two flights were dedicated to documenting the IN concentrations in clear skies close to the observed clouds. Cloud-top temperatures ranged from $-6^{\circ}$ to $-30^{\circ} \mathrm{C}$ for the stratiform cloud cases sampled. Droplet concentrations were generally low $\left(\sim 10 \mathrm{~s} \mathrm{~cm}^{-3}\right)$, but two cases exhibited concentrations in the $100 \mathrm{~s} \mathrm{~cm}^{-3}$. Liquid water contents varied between $\sim 0.1$ and $1 \mathrm{~g} \mathrm{~m}^{-3}$. All cases had ice precipitation. Figure 5 presents a typical flight pattern for the UND Citation; detailed in situ measurements of cloud properties were obtained by alternate Eulerian and Lagrangian spirals over each of the two ground sites, interspersed by porpoise legs between the two sites to sample the horizontal and vertical variability.

RESULTS. A number of outstanding cases were observed during M-PACE. Because a complete overview of all of the cases would be excessive, we instead present results from three cases. The following cases are roughly characteristic of the clouds that occurred during M-PACE: a single-layer boundary layer stratocumulus case (9-11 October), a cirrus case during the second transition (17 October, from regime II to III) period, and a complicated, multilayer stratus case during the first transition (6 October, from regime I to II).

From 9 to 11 October was characterized by low-level northeasterly flow off the pack ice and over the ocean that ultimately reached the NSA. Persistent low-level clouds under a sharp inversion were observed for the entire period, with no mid- or upper-level clouds. Three missions were flown during this period, including a combined Proteus-Citation mission on the 10th to coincide with a close Terra overpass. Figure 6 presents PARSL radar/lidar measurements for a 30 -min period centered on the time of a Citation downward spiral. The figure reveals a cloud top increasing from about 1200 to $1300 \mathrm{~m}$ through the period (top panel), while the lidar shows a liquid cloud base at $\sim 800 \mathrm{~m}$ (approximately the bottom of the zero-valued depolarization ratio layer in the bottom panel). Note that the lidar saturates in the liquid layer. The ceilometer shows the cloud base varying between 800 and $850 \mathrm{~m}$ during this period. The radar image suggests that shafts of ice precipitation and/or drizzle (higher reflectivities) were present throughout the cloud layer, while the higher depolarization values below cloud indicate ice precipitation.

The in situ measurements from the Citation downward spiral reveal a similar picture. Figure 7 shows local cloud base and top slightly below $900 \mathrm{~m}$ and just above $1300 \mathrm{~m}$, slightly higher but close to the values observed by the remote sensing instruments. Cloud-top values for temperature, liquid water content, and mean diameter were $-16.9^{\circ} \mathrm{C}, 0.36 \mathrm{~g} \mathrm{~m}^{-3}$,
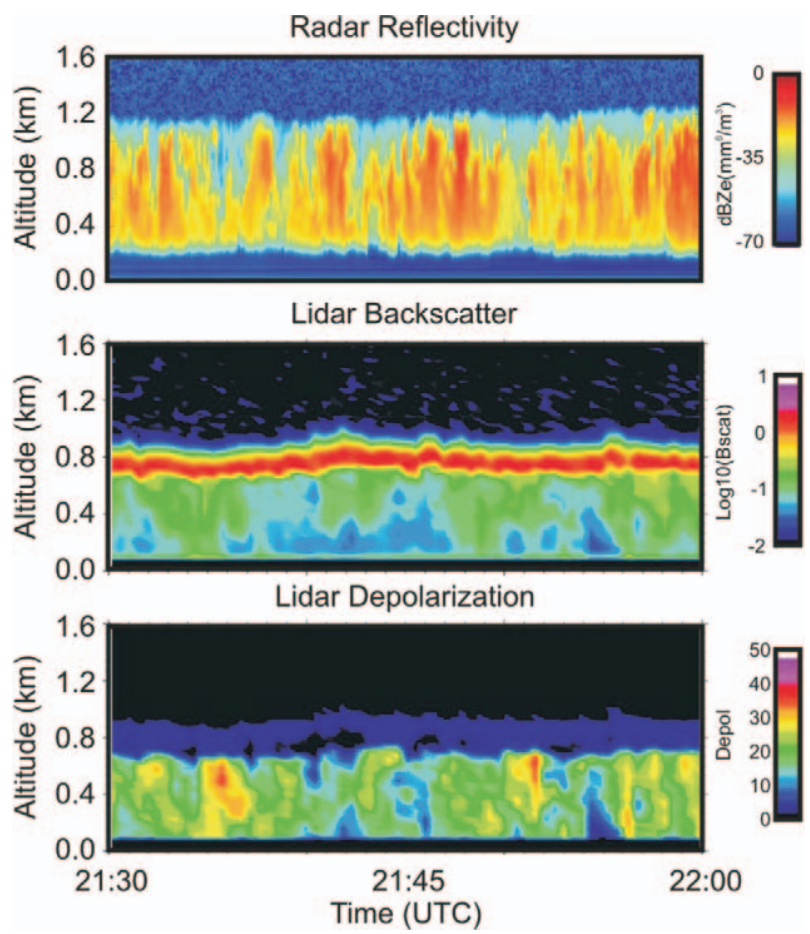

FIG. 6. PARSL (top) radar reflectivity, (middle) lidar backscatter, and (bottom) depolarization for the UND Citation overflight on 10 Oct 2004. 
and $25 \mu \mathrm{m}$, respectively, while the droplet number concentration remained approximately constant at $25 \mathrm{~cm}^{-3}$ throughout the cloud layer. These values are representative of most flights during this 3-day period, with one notable exception-the number concentration varied considerably $\left(20-150 \mathrm{~cm}^{-3}\right)$ between days, and even between flights on the same day. From these changes it appears likely that small changes in synoptic flow can produce significant changes in cloud microphysical characteristics, presumably because of changes in the source region of the air. Although some drizzle drops were detected by the $1 \mathrm{D}$ cloud probe (1DC) and 2D cloud probe (2DC) throughout this period, these drops were small (typically $<100 \mu \mathrm{m}$ ), so the 2DC numbers may be taken as a proxy for the presence of ice crystals. The approximate ice water content can then be deduced from the 2DC and HVPS data using a mass-diameter relationship calibrated with CVI total water measurements in all-ice conditions. The intermittency of ice in the profile confirms the conclusion drawn from the radar measurements-that ice is present in small pockets intercepted occasionally during the spiral.

The imaging and sizing probes provide a view of the particle size distributions and particle types throughout the spiral. Particle size distributions for 30-s flight segments were constructed from the Forward Scattering Spectrometer Probe (FSSP), 1DC and 2DC, and HVPS. These distributions reveal not only a narrow cloud drop distribution throughout the cloud layer, but also the presence of low concentrations of large precipitation particles (up to $1-\mathrm{cm}$ maximum dimension) all the way up to cloud top (Fig. 8). The Cloud Particle Imager (CPI) reveals the presence of drizzle at cloud top, with some irregular particles being detected at cloud base, while images from the HVPS reveal the presence of large, irregular ice crystals all the way up to cloud top (Fig. 9).

The surface-based remote sensing data are critical to provide a detailed look at the processes and prop- b) Water Content

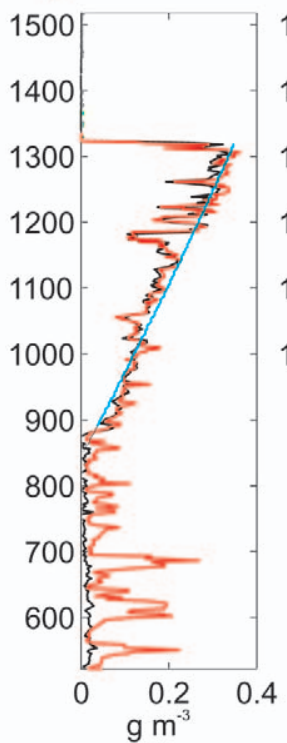

c) Mean Diameter

d) Concentration
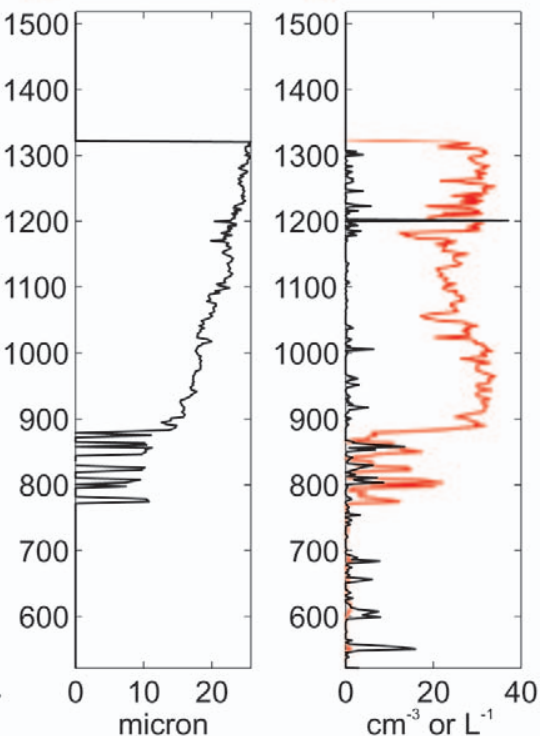

FIG. 7. UND Citation in situ measurements from a single spiral over Oliktok point at 2I45 UTC 10 Oct 2004, corresponding to the PARSL observations Fig. 6. (a) Temperature and (b) liquid (measured and calculated adiabatic) CVI (red); c) mean diameter from the FSSP; and (d) number concentration from the FSSP (red) and 2DC probes.

erties of Arctic clouds. Data of the ARM millimeter cloud radar (MMCR) and lidar data are presented in Fig. 10 for the single-layer stratus event, but for an earlier period than discussed above. Again, the time-height reflectivity plot in the top panel reveals a precipitating stratus layer consisting of short bursts of higher-reflectivity cores, the magnitude of which suggests that the scatterers must be larger ice crystals rather than smaller drizzle drops. Cloud base, as indicated by the lidar, fluctuates by several hundred meters over the 30 -min period, with a tendency toward lower heights in heavy precipitation. The few cloud-base excursions to the surface are likely the result of low-level snow preventing detection of the real base. Tops fluctuate between 1250 and $1450 \mathrm{~m}$.

The MMCR commenced collection of velocitypower spectra just before M-PACE, the analysis of which provides further insight into the microphysical characteristics of the layer. The spectrograph (reflectivity contours in the velocity-height plane) reveals contributions to the total reflectivity from two populations with distinct vertical velocity characteristics. In this spectrograph (Fig. 10, middle), the velocity convention used is (-) for movement away from the radar, such that precipitation will tend to have (+) velocities and updraft (-) velocities. With this knowledge, the two populations may then be identified as nonprecipitating and precipitating hydrometeors, 

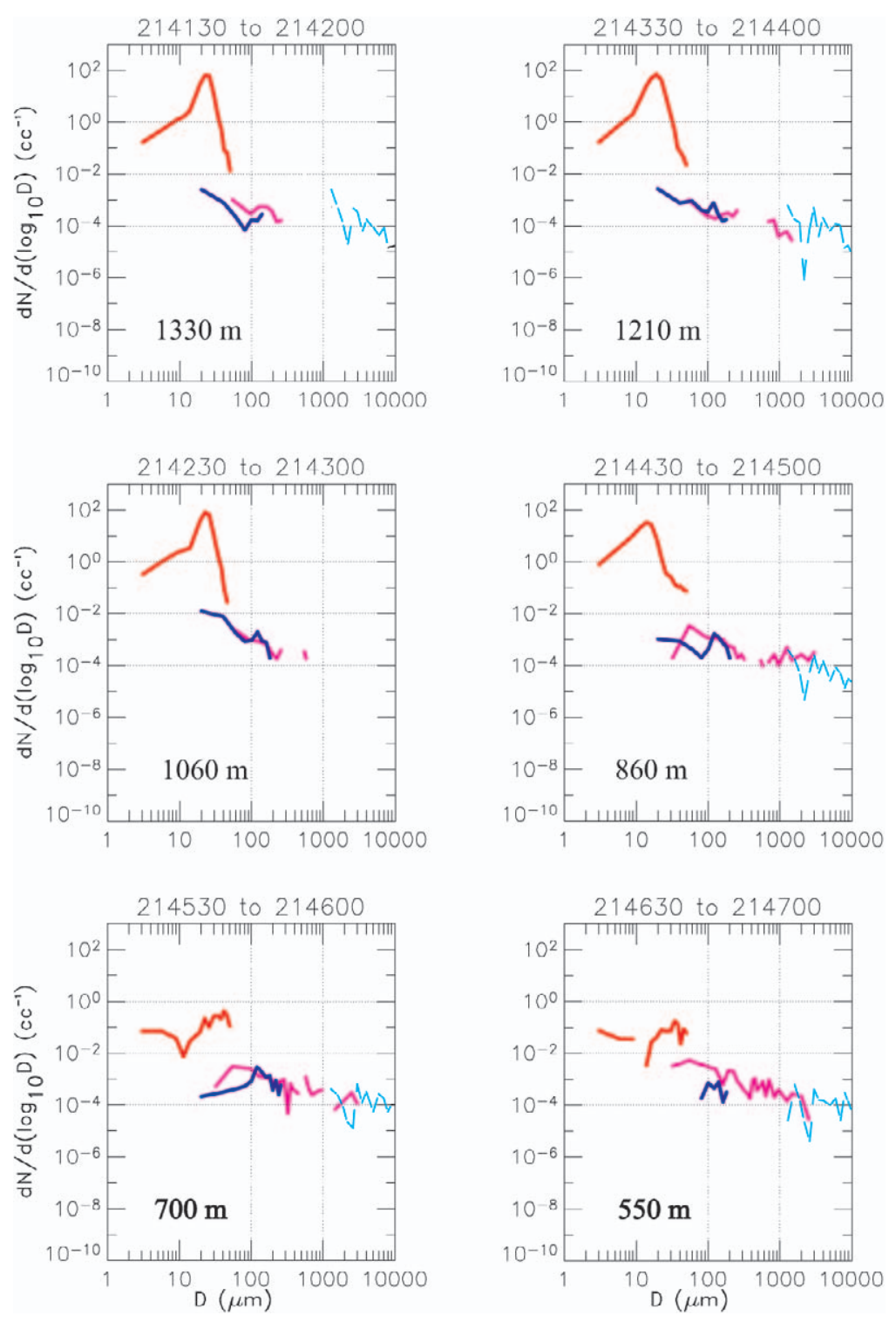

FIG. 8. Example of 30 -s-averaged size distributions measured between 2140 and 2147 UTC 10 Oct 2004 for the same profile as that shown in Fig. 7. The distributions are derived from FSSP, IDC and 2DC, and HVPS probes (see McFarquhar et al. 2005).

which are to the left and right, respectively, of the vertical line on the spectrograph. Following the analysis of Shupe et al. (2004), and assuming that the upward-moving hydrometeor population is liquid, it is then possible to separate contributions to the total reflectivity from water and ice. This then allows for the calculation of liquid water content (LWC) and vertical velocity (bottom panel). The liquid water contribution to the reflectivity maximizes at $-17 \mathrm{dBZ}$, a value close to the upper range expected for nonprecipitating liquid clouds (Frisch et al. 1995). Using the reflectivity-LWC relationship from Shupe et al. (2001), these reflectivity values correspond to LWC values similar to those in Fig. 7, lending confidence that this approach is feasible.

The 17th of October was characterized by mid- and upper-level clouds advecting over the M-PACE domain in advance of a strong front that would pass over Barrow on 19 October. The soundings at Barrow revealed a deep, moist layer between 500 and $250 \mathrm{hPa}$ with humidity peaking between 505 and $460 \mathrm{hPa}$. A dry layer separated this upper-level moist layer from a lower-level thin, moist layer at $650 \mathrm{hPa}$. Both the Citation and the Proteus sampled the cloud system. Initially, the Proteus flew over the highest clouds tops, serving as a remote sensing platform, whereas the Citation did spirals through most of the cloud decks. Figure 11 shows a cross section from the Proteus nadir cloud-detection lidar from an overpass over the Barrow ARM site and a time-height cross section from the ARM MMCR reflectivity of the system as it drifted over. These images reveal a complicated layered cloud structure with multiple precipitating cirrus layers over a midlevel deck associated with the moisture layer at $500 \mathrm{hPa}$. The lower panel shows a high-resolution image from the University of Alaska Fairbanks lidar of the midlevel cloud layer, revealing a thin (50 m thick) liquid cloud layer consisting of small elements over patchy ice clouds.

The observers in the Citation noted that the sky over Barrow was clear of clouds when they arrived over Barrow at 2030 UTC, although the lidars detected optically thin cloud layers between 7.5 and $10 \mathrm{~km}$ (optical depth $\tau \sim 0.08$ from HRSL) and another layer between 5.5 and $6.3 \mathrm{~km}(\tau \sim 0.02)$. The Citation did a profile to the west of Barrow through the thicker cloud deck seen on the left-hand side of the Proteus lidar image in Fig. 11a. The in situ measurements from this profile taken at 2126 UTC (Fig. 12) show a thin liquid cloud layer at $4570-4720 \mathrm{~m}$, located below and connected by precipitation to several layers of cirrus found between 7000 and $9100 \mathrm{~m}$. The temperature of this liquid layer was approximately $-22^{\circ} \mathrm{C}$, and the LWC 
was small at $50 \mathrm{mg} \mathrm{m}^{-3}$. The remote sensing instruments indicate that the Citation did not penetrate through the uppermost cirrus layer. The maximum IWC observed in the cirrus was $60 \mathrm{mg} \mathrm{m}^{-3}$, with bullet rosettes being the dominant habit. Mean crystal sizes increased from $100 \mu \mathrm{m}$ at the cirrus cloud top to $200 \mu \mathrm{m}$ at the base.

After the Citation departed, the Proteus descended into the upper cirrus layer to perform a closure study with the University of Wisconsin scanning high-resolution interferometer sounder (S-HIS) instrument on board the Proteus. The S-HIS is an aircraft-based version of the ARM AERI that provides accurate measurements of the infrared spectrum at high spectral resolution. Measurements from this experiment are illustrated in Fig. 13, with AERI measurements of the downwelling radiance at the ground and S-HIS measurements of the upwelling and downwelling radiance within and above cirrus clouds on 17 October 2004. These data are being used to assess capabilities to measure cloud microphysical properties from the interferometers.
On 6 October, low-level northeasterly flow and a small midlevel disturbance combined to produce a complicated multilayer cloud structure over the North Slope (Fig. 14). The highest cloud tops extended to $4.5 \mathrm{~km}$ at times (Fig. 14a), although the dominant layer during the period shown had tops between 3.3 and $3.5 \mathrm{~km}$. This dominant layer had significant ice precipitation, which produced strong backscatter at radar wavelengths causing the multilayered structure below to be mostly obscured in the radar reflectivity profile (Fig. 14a). However, the narrow-beam lidar reveals the complicated layer structure below. Up to six liquid cloud layers can be discerned in the lidar depolarization ratio image (Fig. 14b), with individual liquid layers appearing in patches separated by ice precipitation shafts (Fig. 14c). The dominant hydrometeor-type map (Fig. 14c) is derived from combined lidar and radar information, through the use of backscatter and depolarization measurements from the HRSL, along with reflectivity and vertical velocity measurements from the MMCR (Greenberg 2005). Individual liquid cloud layers vary from 50
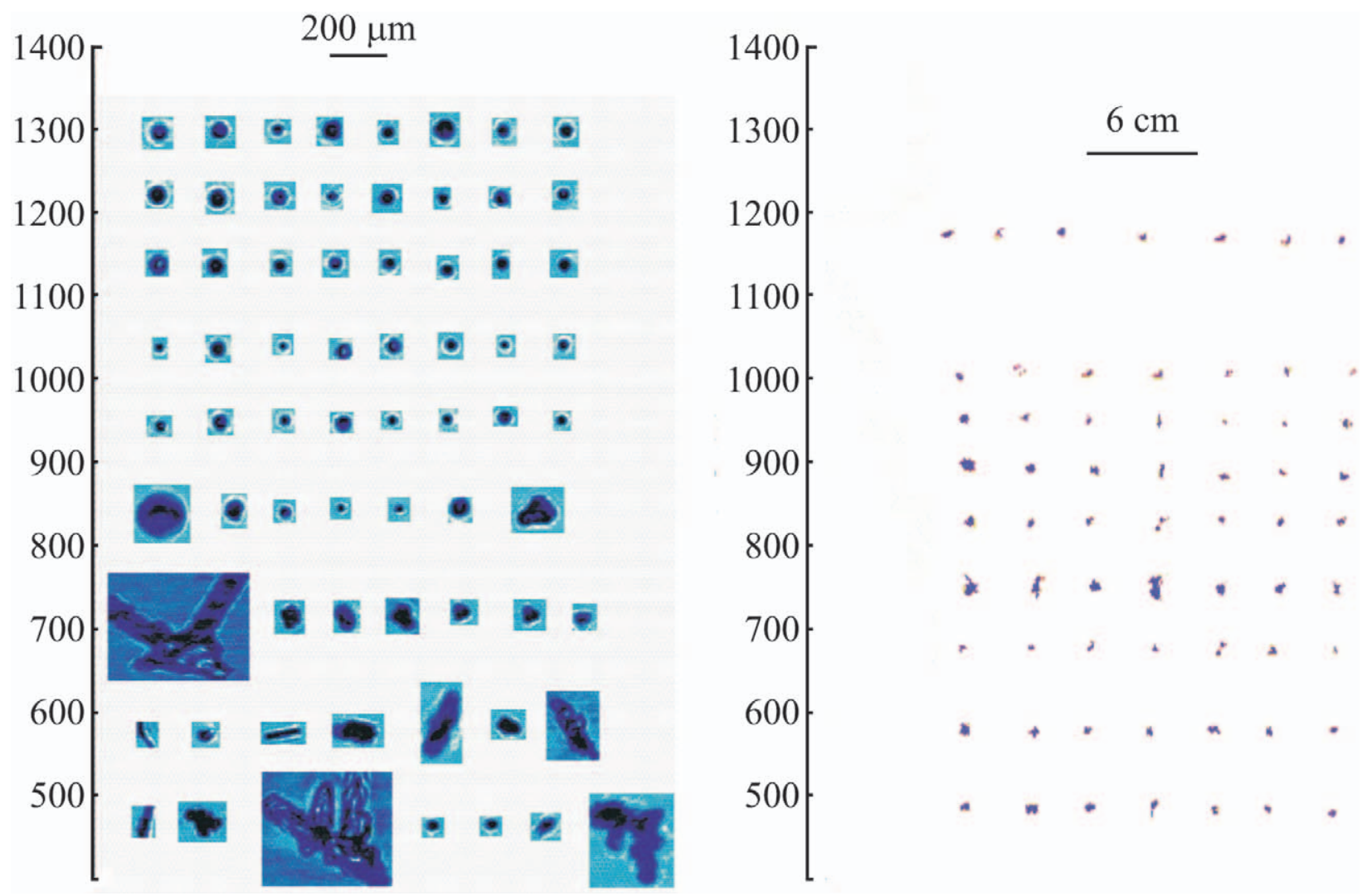

FIG. 9. Examples of selected CPI and HVPS images measured between 2140 and 2147 UTC 10 Oct 2004 for the same profile as that shown in Figs. 7 and 8. The smaller spherical images near cloud top (CPI) are small drizzle or supercooled drops. Larger ice crystal images show dominance of irregular and rimed crystal shapes. Even though the largest crystals measured by HVPS are more frequent near and below cloud base, they can occur throughout depth of cloud (see McFarquhar et al. 2005). 

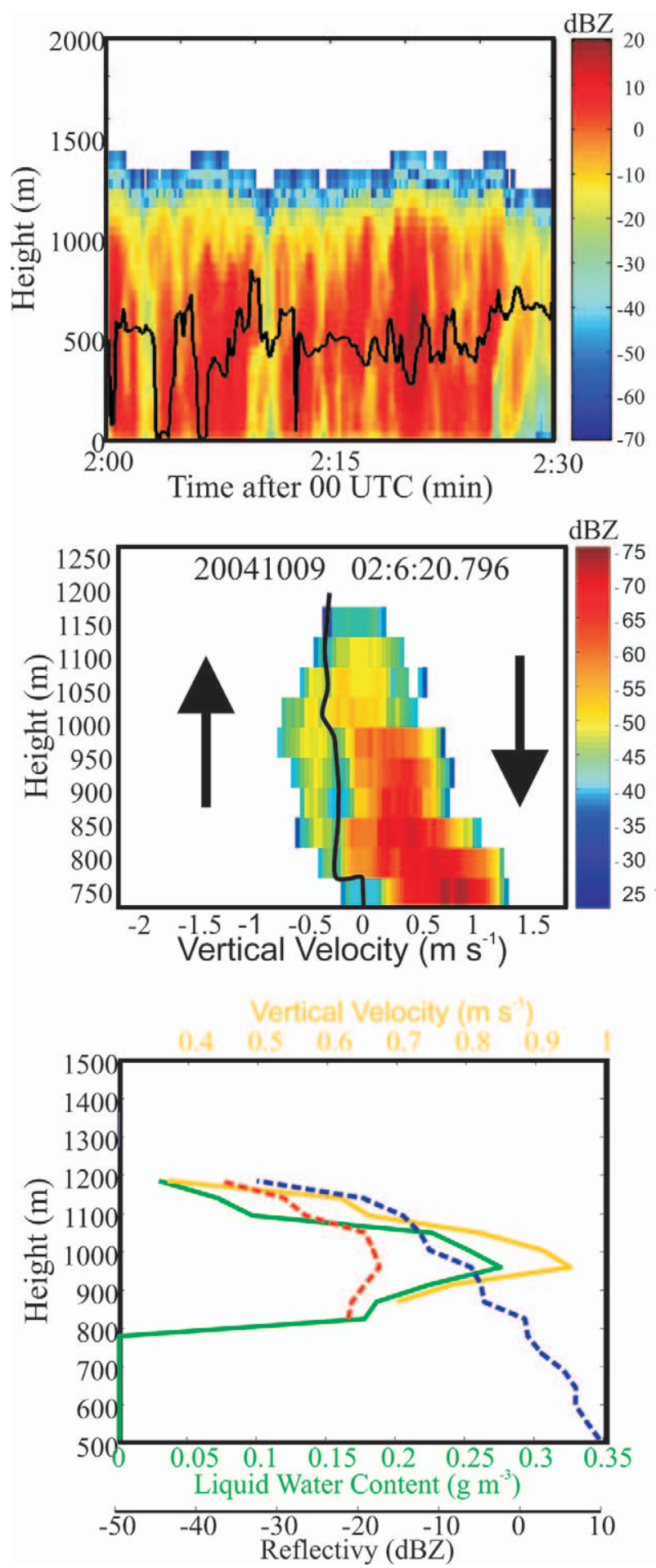

FIG. I0. MMCR analysis for a single profile at 0206 UTC 9 Oct 2004. (top) The MMCR reflectivity and lidar-detected cloud base, (middle) an MMCR spectrograph, and (bottom) retrieved profiles from the spectrograph analysis are shown. The bold dashed lines represent the reflectivity attributed to the liquid (red) and ice (blue) particles in the cloud, while profiles of retrieved liquid water content (blue) and vertical velocity (red) are indicated by the thin solid lines.
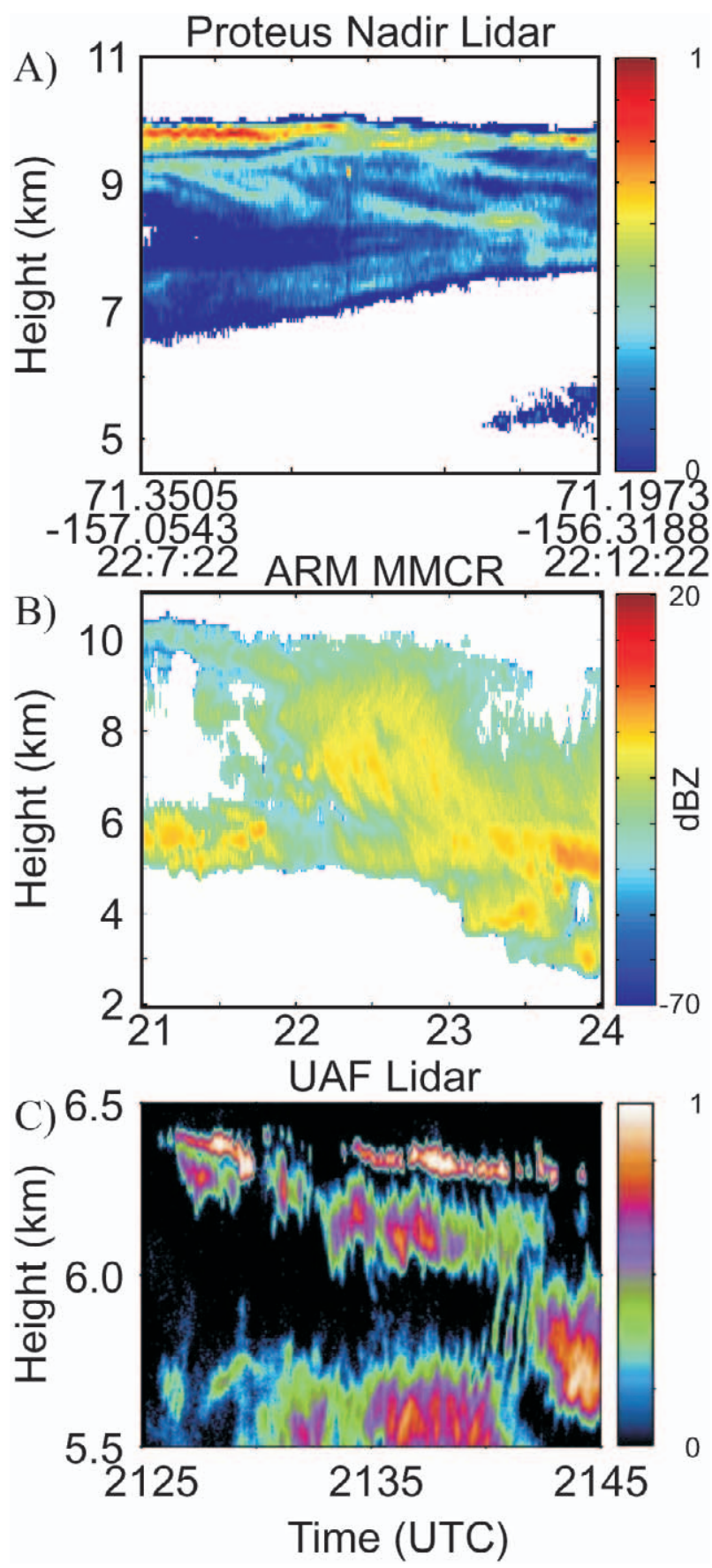

FIG. II. Proteus nadir cloud detection lidar rangecorrected backscatter, ARM MMCR reflectivity, and University of Alaska depolarization lidar backscatter of the cirrus case day of 17 Oct 2004.

to $300 \mathrm{~m}$ in depth, with optical depths of $0.5-2$ for layers that were penetrated. Interestingly, the lidar backscatter between the liquid layers was characteristic of values expected from liquid haze, even while the radar measured reflectivity values of $20 \mathrm{dBZ}$. Together, these measurements suggest that the precipitating ice between the layers consisted of large 
ice particles of very low concentration, such that they produced high reflectivities for that larger radar volume, but were missed by the narrow lidar beam.

The in situ measurements from the Citation spiral over Barrow reveal a similar picture. The aircraft was unable to descend into the lowest cloud layer, but did sample several distinct liquid layers (Fig. 15), each of which was capped by a temperature inversion, with low ice crystal concentrations between layers. The profiles of the microphysical properties for most of the layers are consistent with the dynamically quiescent clouds suggested by aircraft vertical velocities, the exception being the layer at $2600 \mathrm{~m}$ where LWC and drop diameter increase linearly with height. At the time of penetration the topmost cloud was experiencing heavy ice precipitation, seen in both the in situ and radar reflectivity profiles (Fig. 14a at 1915 UTC). The presence of precipitation may explain the irregularities in the microphysical characteristics of the profiles. These characteristics are inconsistent with the radar cloud tops during this period that suggest more active, but small, convection. Indeed, the Citation did measure a vertical velocity pulse of $1.8 \mathrm{~m} \mathrm{~s}^{-1}$ during the profile. The vertical velocity fluctuated between plus and minus $1 \mathrm{~m} \mathrm{~s}^{-1}$ in the second layer, suggesting that this deck, though also precipitating, was experiencing stronger forcing, the origin of which is not clear at this stage.

An additional objective of M-PACE was to provide in situ measurements to evaluate remote sensing

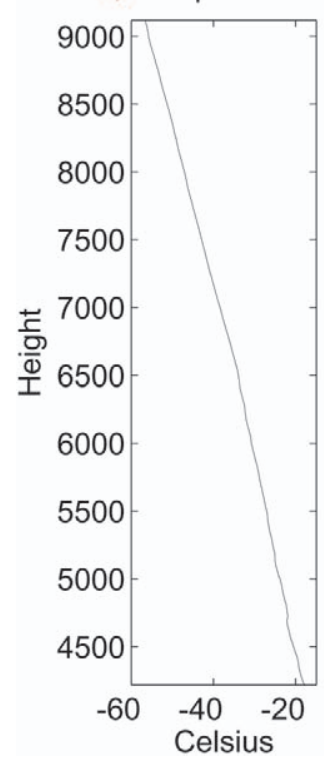
backscatter data. b) Water Content

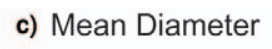

d) Concentration
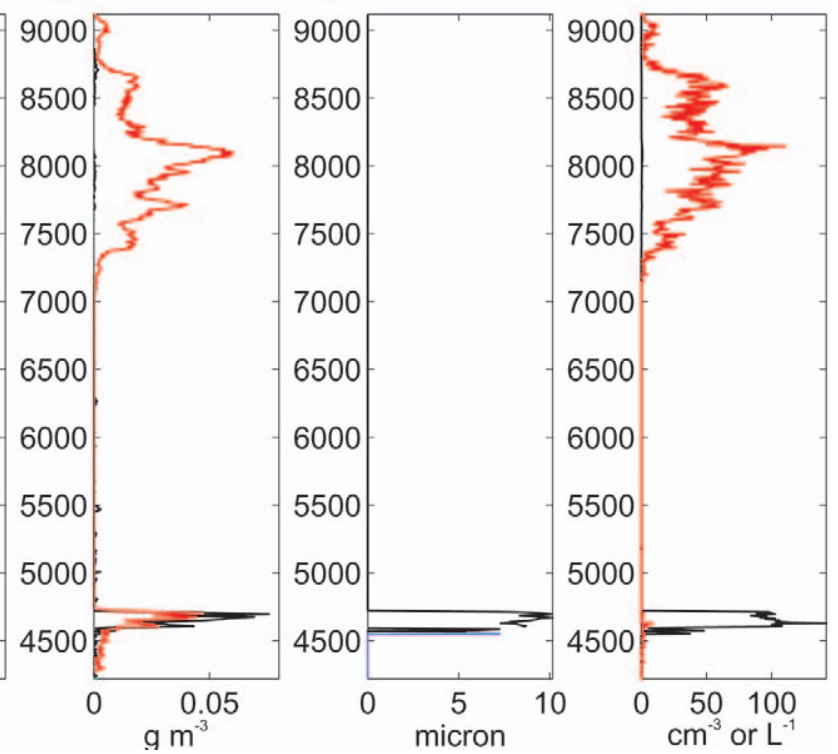

Fig. 12. Same as Fig. 7, but for 2126 UTC 17 Oct 2004.

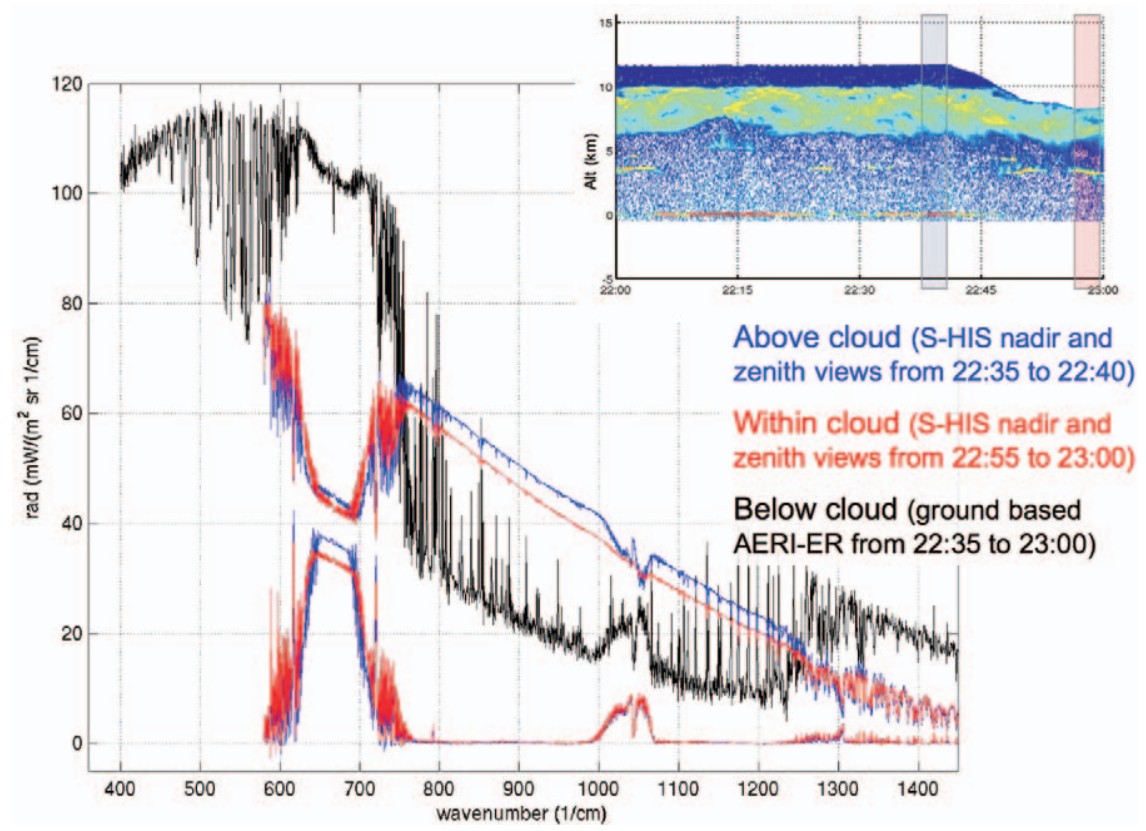

Fig. 13. Ground-based AERI and S-HIS measurements (up and down from a 9- and 12-km flight altitude) at Barrow, AK, on 17 Oct 2004 during the M-PACE experiment. The cloud boundary inset is based on onboard lidar measurements. This field experiment provided the opportunity to evaluate two recently developed retrievals for the microphysical properties of mixed-phase clouds from ground-based passive remote sensors. One technique utilizes thermal infrared observations in the $8-13$ and $17-24-\mu \mathrm{m}$ bands observed by the AERI (Turner 2005), whereas the other uses observations in the 1000-1700-nm band (Daniel et al. 2002, 2006). 

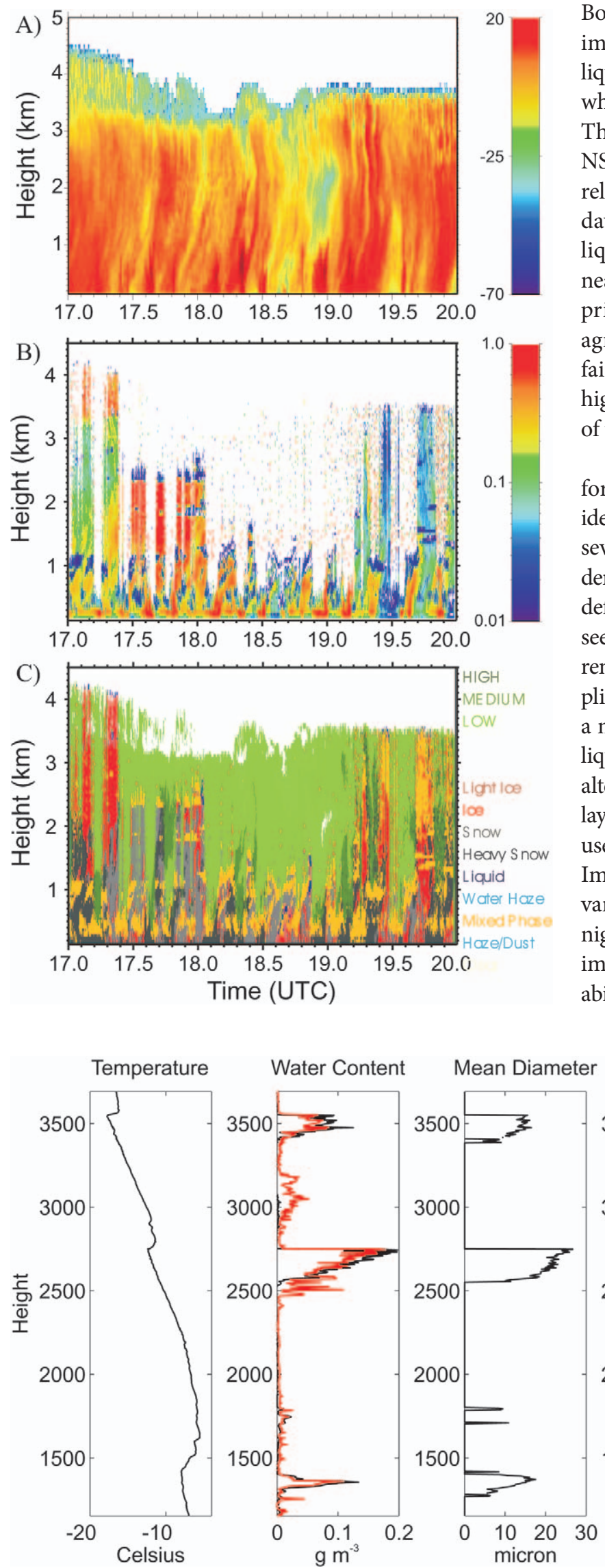

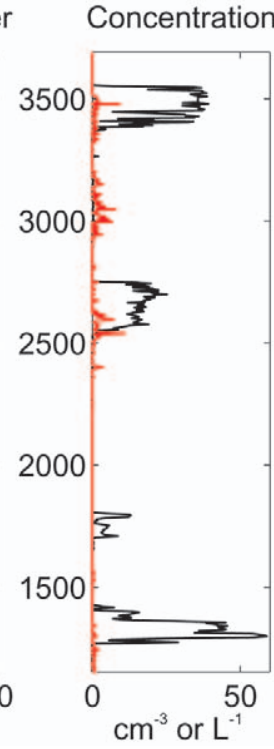

Both techniques take advantage of the changes in the imaginary part of the refractive index of ice relative to liquid water, taking observations in wavelength regions where ice and liquid can be spectrally differentiated. The near-infared spectrometer was deployed at the NSA site from 12 September to 21 October; because it relies on scattering sunlight as its signal, it only makes daytime measurements. Figure 16 demonstrates the liquid water path (LWP) retrieved using the AERI, near-IR spectrometer, and the MWR for a single layer, primarily liquid cloud on 14 September 2004. The agreement between the AERI and near-IR methods is fairly good, while the MWR retrievals are significantly higher for much of the period. A more detailed analysis of this case is given in DAN.

M-PACE observations are also serving as the basis for the development of new algorithms for satellite identification of mixed-phase clouds. Both aircraft flew several special flight patterns underneath and coincident with satellite overpasses. It should be noted that the definition of what is considered a mixed-phase cloud as seen from a satellite differs from that for ground-based remote sensing because of the big differences in sampling volume. In the context of satellite observations, a mixed-phase cloud is defined as that where ice and liquid coexist in the same satellite-sampling volume or, alternatively, where ice and liquid are found in stratified layers within the satellite footprint. One new algorithm uses the infrared channels of the Moderate-Resolution Imaging Spectroradiometer (MODIS), and has the advantage that it can be applied equally well to day- and nighttime scenes (Spangenberg et al. 2006). Successful implementation of this algorithm will extend current abilities to detect mixed-phase cloud systems over the Arctic and will allow for a better understanding of their spatial extent and relationship to synoptic-scale weather systems.

This new technique is illustrated on MODIS data taken at 2210 UTC 8 October 2004. The $11-\mu \mathrm{m}$ brightness temperature

Fig. 14 (top left). (a), (b) MMCR radar reflectivity and (c) radar/lidar cloud phase mask for the UND Citation flight over Barrow on 6 Oct 2004.

Fig. I5 (LefT). Same as Fig. 7, but for 6 Oct 2004. 


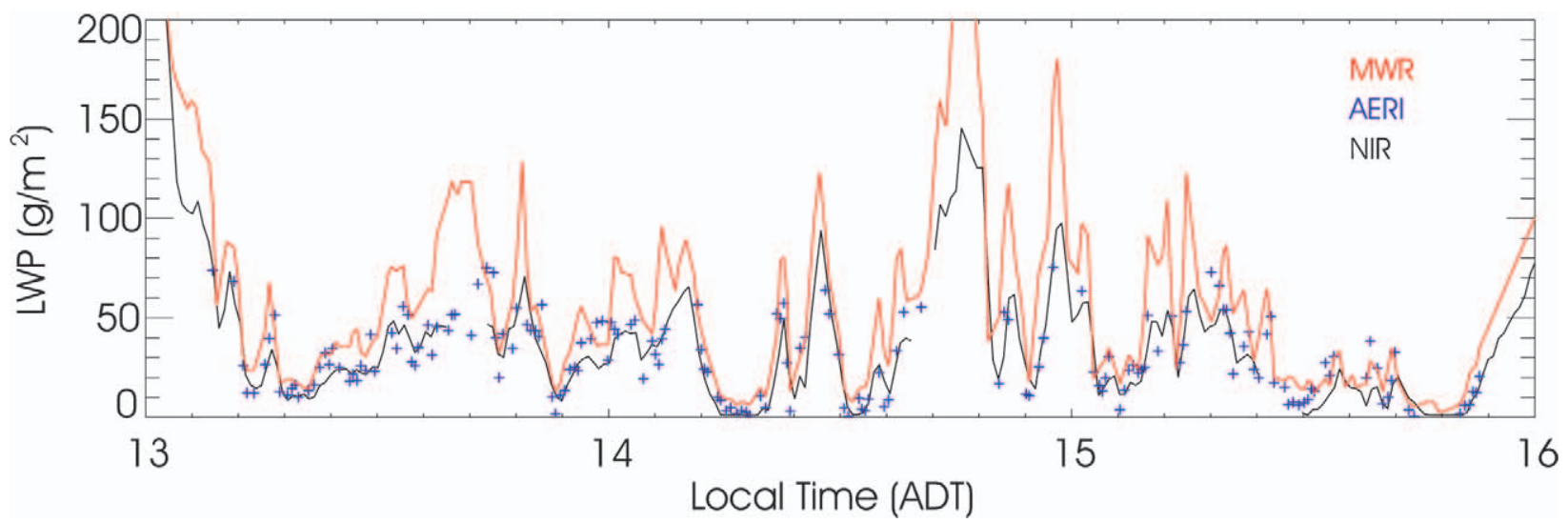

Fig. 16. Comparison between three liquid water content retrieval algorithms relying on different parts of the electromagnetic spectrum: microwaves (red line, MWR), infrared bands (blue line, AERI), and near-infrared bands (black line, near-infrared spectrometer).
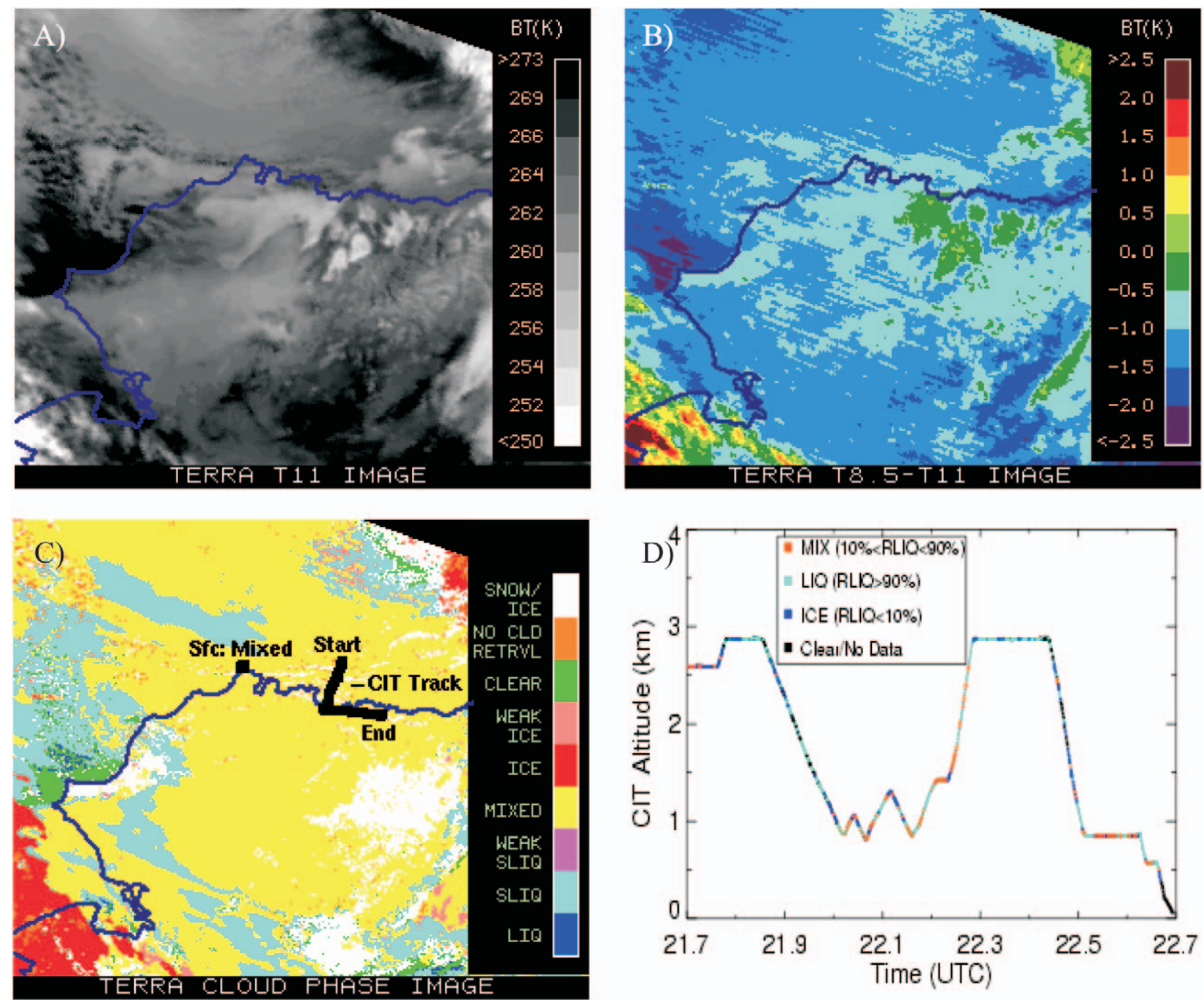

FIG. 17. Terra MODIS imagery and in situ cloud phase determination from the UND Citation for 2210 UTC 8 Oct 2004. (a) II- $\mu \mathrm{m}$ brightness temperature, (b) brightness temperature difference between 8.15 and II $\mu \mathrm{m}$, (c) cloud phase mask, with Citation flight track and surface-based phase retrieval, and (d) Citation cloud phase. The surface-based phase retrieval and CIT flight track are also plotted in (c). The LIQ and SLIQ terms in (c) represent liquid and supercooled liquid water, respectively. 
(Fig. 17a) shows a stratus cloud with values ranging from 255 to $265 \mathrm{~K}$. Many of the cloud systems are mixed with supercooled liquid tending to be found in areas where the $11-\mu \mathrm{m}$ brightness temperature values are somewhat higher. The brightness temperature difference between 8.5 and $11 \mu \mathrm{m}$ (Fig. 17b) is a general indicator of the relative amount of liquid at the top of mixed-phase clouds, with lower values indicating more liquid (Fig. 17c). Low values, below about $-0.35 \mathrm{~K}$, indicate low-level mixed-phase clouds with tops of mostly liquid water, which is the case for most of the image. The surface remote sensors indicated mixed-phase cloud over Barrow at the Terra overpass time, which is in general agreement with the MODIS phase retrieval.

An hour-long segment of the Citation's flight track centered at the Terra overpass time is shown on the MODIS phase image. The corresponding altitude and in situ phase determinations for this segment are plotted in Fig. 17d. The in situ total and liquid water content measurements were combined to obtain the relative amount of liquid along the flight path. These time series data reveal a similar picture of the phase composition of clouds deduced from other days, showing many change overs from liquid- $\left(R_{\text {liq }}>90 \%\right)$ to ice- $\left(R_{\mathrm{liq}}<10 \%\right)$ dominated samples as the aircraft ascended/descended through multiple cloud layers. In addition, the plot reveals a few regions containing more balanced mixtures of liquid and ice. This back-and-forth transition between liquid and ice is consistent with the satellite retrieval of mixed phase for the entire cloud system.

SUMMARY AND DISCUSSION. The MixedPhase Arctic Cloud Experiment successfully documented the microphysical structure of Arctic mixed-phase clouds, with multiple in situ profiles collected in both single- and multilayer clouds over the two ground-based remote sensing sites at Barrow and Oliktok Point. Liquid was found in clouds with

FIG. 18. Ice nuclei concentration (60-s average and wide region, and corrected to STP) as a function of CFDC processing temperature. Data are limited to measurements for which processing humidity was greater than water saturation, in order to capture deposition, immersion, and condensation freezing nuclei. Individual flights are delineated by symbol. IN concentrations plotted at $0.001 \mathrm{~L}^{-1}$ were below background levels, and constituted $85 \%$ of the measurements. Thus, while many of the IN measurements shown fall between I and $10 \mathrm{~L}^{-1}$, project-averaged IN concentrations were generally below $\mathrm{I} \mathrm{L}^{-1}$. cloud-top temperatures as cold as $-30^{\circ} \mathrm{C}$, the coldest cloud-top temperature warmer than $-40^{\circ} \mathrm{C}$ sampled by the aircraft; in clouds forming as the result of strong surface forcing (regime II); and also in weakly forced stratiform clouds (regimes I and III). This result confirms the SHEBA finding that mixed-phase clouds are common in the Arctic at very low temperatures, showing it is true also in the coastal regions (of the North Slope). From the differences in the forcing of the clouds it may be concluded that the cause of the persistent liquid in these cold, ice-precipitating clouds is not in the dynamical characteristics of the clouds, but must be microphysical in origin, as was hypothesized (Harrington et al. 1999; Morrison et al. 2005). Moreover, M-PACE added significantly to the FIRE-ACE in situ dataset, not only providing more profiles, but also adding another season.

The remote sensing instruments suggest that ice was present in low concentrations, mostly concentrated in precipitation shafts, although there are indications of light ice precipitation present below the optically thick single-layer clouds. The prevalence of liquid down to these low temperatures potentially could be explained by the relatively low measured ice nuclei concentrations (Prenni et al. 2007; Fig. 18). Although number concentrations of cloud droplets were generally low $\left(<90 \mathrm{~cm}^{-3}\right)$ in these mixed-phase clouds, on two flights mean layer concentrations exceeded $300 \mathrm{~cm}^{-3}$-in an elevated stratocumulus on 5 October, but also in surface-forced convection on the second flight on 9 October, when concentrations reached $500 \mathrm{~cm}^{-3}$. These observations suggest that airmass properties can change with small changes

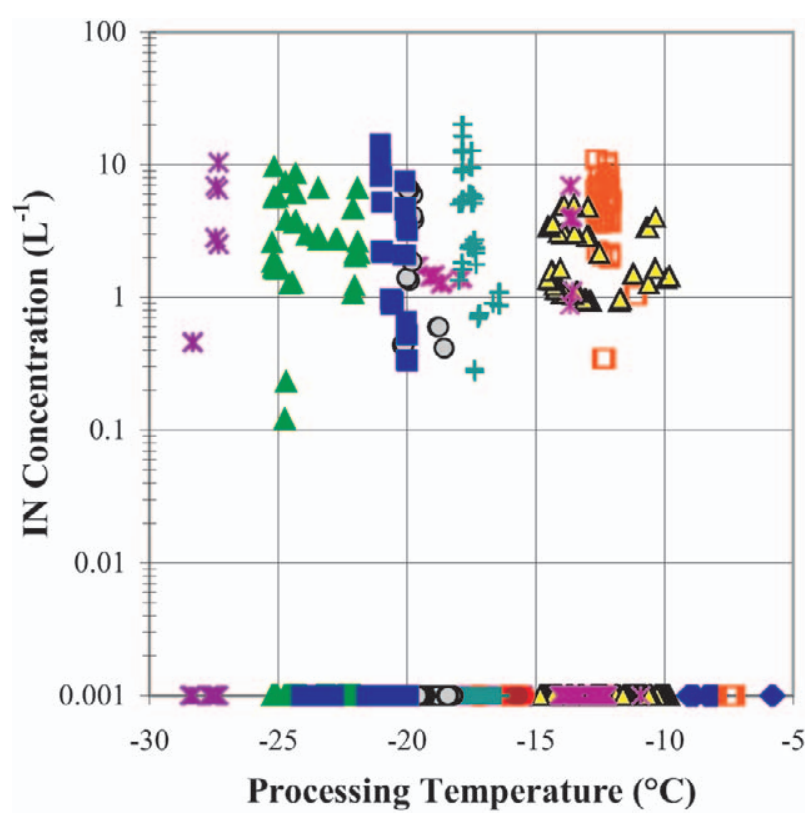


in the synoptic flow pattern, presumably associated with local pollution sources. Flights into Arctic cirrus clouds revealed microphysics properties very similar to their midlatitude in situ-formed cousins, with bullet rosettes as the dominant ice crystal habit.

Several new, advanced remote sensing instruments were deployed in the Arctic for the first time. The spectra processing and recording of the ARM MMCR measurements promise to provide a means of separating the radiatively important cloud contribution to the reflectivity from the precipitation contribution, making it possible to retrieve more accurately the properties important to the surface energy budget. The Arctic High Spectral Resolution Lidar documented the structure of multiple layers of thin liquid clouds in precipitating ice, and because it is fully calibrated this lidar can be used to quantify those hard-to-detect layers. The combination of surface-based and spaceborne remote sensors present during M-PACE allowed for the development of a comprehensive dataset that can be used to develop new cloud property retrieval algorithms or evaluate existing ones. All M-PACE data are freely available for research purposes (after registration at the same site), and can be found online at http://iop.archive. arm.gov/ under IOP data/2004/nsa/mpace.

ACKNOWLEDGMENTS. We would like to acknowledge all the people who endured difficult conditions in the field to collect these data. We thank Richard Flanders of the University of Alaska Fairbanks for hosting us at the NSF LTER site at Toolik Lake, the staff of the Oliktok Point Defense Early Warning site for hosting PARSL, Dr. Peter Q. Olsson and his staff at the Alaska Experiment Forecast Facility, University of Alaska Anchorage for their help with the RAMS forecast model, and the staff of the DOE ARM NSA operations for hosting (and protecting) personnel at Barrow and Atqasuk. This research was supported by the Office of Biological and Environmental Research of the U.S. Department of Energy as part of the Atmospheric Radiation Measurement and Atmospheric Radiation Measurement Unmanned Aerial Vehicle programs. We thank the three anonymous reviewers for their very helpful input.

\section{REFERENCES}

ACIA, 2005: Impacts of a Warming Arctic: Arctic Climate Impact Assessment. Cambridge University Press, $144 \mathrm{pp}$.

Ackerman, T. P., and G. M. Stokes, 2003: The Atmospheric Radiation Measurement Program. Physics Today, 56, 38-44.
Avramov, 2005: Objective synoptic typing during mixed-phase Arctic cloud experiment. M.S. thesis, Dept. of Meteorology, The Pennsylvania State University, $89 \mathrm{pp}$.

Curry, J. A., 1986: Interactions among turbulence, radiation and microphysics in Arctic stratus clouds. J. Atmos. Sci., 43, 90-106.

—, F. G. Meyer, L. F. Radke, C. Brock, and E. E. Ebert, 1990: Occurrence and characteristics of lower tropospheric ice crystals in the Arctic. Int. J. Climatol., 10, 749-764.

- W. B. Rossow, D. A. Randall, and J. L. Schramm, 1996: Overview of Arctic cloud and radiation characteristics. J. Climate, 9, 1731-1764.

_- J. O. Pinto, T. Benner, and M. Tschudi, 1997: Evolution of the cloudy boundary layer during the autumnal freezing of the Beaufort Sea. J. Geophys. Res., 102 (D12), 13 851-13 860.

- , and Coauthors, 2000: FIRE Arctic clouds experiment. Bull. Amer. Meteor. Soc., 81, 5-29.

Daniel, J. S., S. Solomon, R. W. Portmann, A. O. Langford, C. S. Eubank, E. G. Dutton, and W. Madsen, 2002: Cloud liquid water and ice measurements from spectrally resolved near-infrared observations: A new technique. J. Geophys. Res., 107, 4599, doi:10.1029/2001JD000688.

— , and Coauthors, 2006: Cloud property estimates from zenith spectral measurements of scattered sunlight between 0.9 and $1.7 \mu \mathrm{m}$. J. Geophys. Res., 111, D16208, doi:10.1029/2005JD006641.

Eloranta, E. W., 2005: High spectral resolution lidar. Lidar: Range-Resolved Optical Remote Sensing of the Atmosphere, K. Weitkamp, Ed., Springer Series in Optical Sciences, Vol. 102, Springer-Verlag, 460 pp.

Francis, J. A., E. Hunter, J. R. Key, and X. Wang, 2005: Clues to variability in Arctic minimum sea-ice extent. Geophys. Res. Lett., 32, L21501, doi:10.1029/ 2005GL024376.

Frisch, A. S., C. W. Fairall, and J. B. Snider, 1995: Measurement of stratus cloud and drizzle parameters in ASTEX with a $\mathrm{K}_{\alpha}$-band Doppler radar and a microwave radiometer. J. Atmos. Sci., 52, 2788-2799.

Greenberg, S. D., 2005: Objective Arctic cloud phase determination. M.S. thesis, Dept. of Meteorology, The Pennsylvania State University, 64 pp.

Harrington, J. Y., and P. Q. Olsson, 2001: A method for the parameterization of cloud optical properties in bulk and bin microphysical models. Implications for Arctic cloudy boundary layers. Atmos. Res., 57, $51-80$

—, T. Reisin, W. R. Cotton, and S. M. Kreindenweis, 1999: Cloud resolving simulation of Arctic stratus. 
Part II: Transition season clouds. Atmos. Res., 51, 45-75.

Herman, G., and J. A. Curry, 1984: Observational and theoretical studies of solar radiation in Arctic clouds. J. Climate Appl. Meteor., 23, 5-24.

Hobbs, P. V., and A. L. Rangno, 1998: Microstructures of low and middle-level clouds over the Beaufort Sea. Quart. J. Roy. Meteor. Soc., 124, 2035-2071.

Holland, M. M., and C. M. Bitz, 2003: Polar amplification of climate chnage in coupled models. Climate Dyn., 21, 221-232.

Intrieri, J. M., M. D. Shupe, T. Uttal, and B. J. McCarty, 2002a: An annual cycle of Arctic cloud characteristics observed by radar and lidar at SHEBA. J. Geophys. Res., 107, 8030, doi:10.1029/2000JC000423.

—, C. W. Fairall, M. D. Shupe, P. O. G. Persson, E. L Andreas, P. S. Guest, and R. E. Moritz, 2002b: An annual cycle of Arctic surface cloud forcing at SHEBA. J. Geophys. Res., 107, 8039, doi:10.1029/ 2000JC000439.

Jiang, H., W. R. Cotton, J. O. Pinto, J. A. Curry, and M. J. Weissbluth, 2000: Cloud resolving simulations of mixed-phase Arctic stratus observed during BASE: Sensitivity to concentration of ice crystals and largescale heat and moisture advection. J. Atmos. Sci., 57, 2105-2117.

Kalkstein, L. S., M. C. Nichols, C. D. Barthel, and J. S. Greene, 1996: A new spatial synoptic classification: Application to air-mass analysis. Int. J. Climatol., 16, 983-1004.

Kattsov, V. M., and E. Källén, 2004: Future climate change: Modeling and scenarios for the Arctic. Impacts of a Warming Arctic: Arctic Climate Impacts Assessment, J. S. Hassoll, Ed., Cambridge University Press, 99-150. [Available online at www.acia.uaf. edu.]

Knuteson, R. O., and Coauthors, 2004: Atmospheric Emitted Radiance Interferometer. Part I: Instrument design. J. Atmos. Oceanic Technol., 21, 1763-1776.

McFarquhar, and Coauthors, 2005: Assessing current parameterizations of mixed-phase clouds using in-situ profiles measured during the mixed-phase cloud experiment. Extended Abstract, 15th ARM Science Team Meeting, Daytona Beach, FL, ARM, 1-14. [Available online at www.arm.gov/publications/proceedings/conf15/extended_abs/mcfarquhar_gm3.pdf.]

Morrison, H., M. D. Shupe, J. O. Pinto, and J. A. Curry, 2005: Possible roles of ice nucleation mode and ice nuclei depletion in the extended lifetime of Arctic mixed-phase clouds. Geophys. Res. Lett., 32, L18801, doi:10.1029/2005GL023614.
Overpeck, J. T., and Coauthors, 2005: Arctic system on trajectory to new state. Eos, Trans. Amer. Geophys. Union, 86, 309-316.

Pinto, J. O., 1998: Autumnal mixed-phase cloudy boundary layers in the Arctic. J. Atmos. Sci., 55, 2016-2038.

- , and J. A. Curry, 1995: Atmospheric convective plumes emanating from leads, 1. Microphysical and radiative processes. J. Geophys. Res., 100, 4633-4642.

,$- \ldots$, and A. H. Lynch, 1999: Modeling clouds and radiation for the November 1997 period of SHEBA using a column climate model. J. Geophys. Res., 104 (D6), 6661-6678.

Prenni, A. J., and Coauthors, 2007: Do aerosols regulate Arctic cloudiness? Bull. Amer. Meteor. Soc., in press.

Randall, D. A., and Coauthors, 1998: Status of and outlook for large-scale modeling of atmosphere-iceocean interactions in the Arctic. Bull. Amer. Meteor. Soc., 79, 197-219.

Sassen, K., 1994: Advances in polarization diversity lidar for cloud remote sensing. Proc. IEEE, Remote Sens. Instruments Environ. Res., 82, 1907-1914.

SEARCH SSC, 2001: SEARCH: Study of Environmental Arctic Change, Science Plan, 2001. Polar Science Center, Applied Physics Laboratory, University of Washington, 89 pp.

Shupe, M. D., T. Uttal, S. Y. Matrosov, and A. S. Frisch, 2001: Cloud water contents and hydrometeor sizes during the FIRE Arctic Clouds Experiment. J. Geophys. Res., 106 (D14), 15 015-15 028.

—, P. Kollias, S. Y. Matrosov, and T. L. Schneider, 2004: Deriving mixed-phase cloud properties from Doppler radar spectra. J. Atmos. Oceanic Technol., 21, 660-670.

—, S. Y. Matrosov, and T. Uttal, 2006: Arctic mixedphase cloud properties derived from surface-based sensors at SHEBA. J. Atmos. Sci., 63, 697-711.

Spangenberg, D. A., P. Minnis, M. D. Shupe, and M. R. Poellot, 2006: Retrieval of cloud phase over the Arctic using MODIS 6.7-12 $\mu \mathrm{m}$ data. Proc. of the 14th Conf. on Satellite Meteorology and Oceanography, Atlanta, GA, Amer. Meteor. Soc., CD-ROM, 8.2.

Stokes, G. M., and S. E. Schwartz, 1994: The Atmospheric Radiation Measurement (ARM) Program: Programmatic background and design of the cloud and radiation test bed. Bull. Amer. Meteor. Soc., 75, 1201-1221.

Stroeve, J. C., and Coauthors, 2005: Tracking the Arctic's shrinking ice cover: Another extreme minimum in 2004. Geophys. Res. Lett., 32, L04501, doi:10.1029/ 2004 GL021810. 
Turner, D. D., 2005: Arctic mixed-phase cloud properties from AERI-lidar observations: Algorithm and results from SHEBA. J. Appl. Meteor., 44, 427-444.

Uttal, T., and Coauthors, 2002: Surface Heat Budget of the Arctic Ocean. Bull. Amer. Meteor. Soc., 83, 255-275.

Vavrus, S., 2004: The impact of cloud feedbacks on Arctic Climate under greenhouse forcing. J. Climate, 17, 603-615.

Walsh, J. E., and W. L. Chapman, 1998: Arctic cloudradiation-temperature associations in observed data and atmospheric reanalyses. J. Climate, 11, 3030-3045.

Wang, X., and J. Key, 2003: Recent trends in Arctic surface, cloud, and radiation properties from space. Science, 299, 1725-1728.
- , and — , 2005a: Arctic surface, cloud, and radiation properties based on the AVHRR Polar Pathfinder data set. Part I: Spatial and temporal characteristics. J. Climate, 18, 2558-2574.

- and - 2005b: Arctic surface, cloud, and radiation properties based on the AVHRR Polar Pathfinder data set. Part II: Recent trends. J. Climate, 18, 2575-2593.

Wang, Z., K. Sassen, D. Whiteman, and B. Demoz, 2005: Arctic mixed-phase cloud microphysical properties retrieved from ground-based active and passive remote sensors. Proc. of the Eighth Conf. on Polar Meteorology and Oceanography, San Diego, CA, Amer. Meteor. Soc., CD-ROM, 6.3.

Zuidema, P., and Coauthors, 2005: An Arctic springtime mixed-phase cloudy boundary layer observed during SHEBA. J. Atmos. Sci., 62, 160-176. 